\title{
Effects of Carbachol on the Excitatory Muscarinic Cholinergic Receptors in Urinary Bladder and Plasma Inflammatory Mediators in Anesthetized Rats
}

\author{
WEN. H, LI. H, DIFEI ZHU, LI WANG AND YANG. P* \\ Department of Anesthesiology, The First Affiliated Hospital of Chengdu Medical College, Chengdu, Sichuan 610000, \\ PR China
}

Wen, et al.: Carbachol effects on the Excitatory Muscarinic Acetylcholine receptor in anesthetized Rats

To observe the effects of muscarinic cholinergic receptor agonist carbachol on urinary bladder function and plasma inflammatory mediators in anesthetized rats. A total of 20 rats were randomly divided into carbachol group and solvent control group, 10 rats in each group. The detection of bladder wall thickness and histological observation were conducted by light microscopy, the changes of urinary bladder function and plasma inflammatory mediators in rats were compared between the two groups. The maximum bladder capacity, static bladder pressure, compliance, bladder wet weight and bladder wall thickness in the carbachol group were significantly higher than those in the solvent control group. Light microscopic evaluation revealed that the detrusor cells in the solvent control group appeared to be in order in terms of size, arrangement and shape, while in the carbachol group the detrusor cells exhibited hypertrophy together with disordered arrangement, diverse morphology and vacuolar degeneration of muscle fibre. The levels of TNF- $\alpha$ and IL-10 in plasma of the carbachol group were significantly lower than those of the solvent control group. In anesthetized rats, the stimulation of muscarinic cholinergic receptors can significantly reduce urinary frequency, increase the volume of bladder storage and decrease systemic inflammatory response.

Key words: Bladder, urinary function, carbachol, anesthetized rats

Urinary dysfunction is a common disease characterized by urinary frequency and urgency, dysuria as well as various kind of urinary incontinence ${ }^{[1]}$. There are some clear reasons, for example, multiple sclerosis causing detrusor hyperreflexia and then gives rise to frequent urination, urinary urgency and urge incontinence, or benign prostatic hyperplasia causing bladder output obstruction $^{[2]}$. However, many of the urinary disorders are idiopathic with unknown cause and conventional treatment does not control the symptoms very well[ ${ }^{[3]}$. Carbachol is a muscarinic cholinergic receptor (MCR) agonist with the effects of promoting gastrointestinal motility, dilating blood vessels and increasing gland secretion. In clinical trials it was previously used in the treatment of flatulence and urinary retention after surgery ${ }^{[4]}$. Recent studies have found that carbachol has obvious anti-inflammatory effects ${ }^{[5,6]}$. However, there are few reports about the effect of carbachol on bladder function. In view of this, the present study was conducted to observe the effect of carbachol injected through tail vein on urinary bladder function and plasma inflammatory mediators in rats and analyze the changes seen in the process so as to provide experimental evidence for the clinical application of carbachol. 
Carbachol was purchased from $\mathrm{ABCR} \mathrm{GmbH}$ and Co.KG. All the drugs were dissolved in distilled water. A total of 20 male Wistar rats, weighing 35-42 $\mathrm{g}$, were provided by the Hebei Experimental Animal Center. The rats were randomly divided as carbachol group and solvent control group containing 10 rats in each group. The dose of carbachol administered to the carbachol group rats was $5.5 \mathrm{~g} / \mathrm{kg}$ and before the first administration, 3 constant urination cycles (6-12 $\mathrm{min}$ ) in each rat were observed to record the maximum bladder capacity, static pressure, bladder compliance, bladder wet weight and bladder wall thickness; after each injection similar observations were made on another 3 constant urination cycles with a dosing interval of $30 \mathrm{~min}$. The rats in the solvent control group were given $0.5 \mathrm{ml} / \mathrm{kg}$ saline 5 times each at an interval of $30 \mathrm{~min}$.

The rats were fixed on an anatomical table and urodynamic measurements were made on each rats in both groups (figs. 1-3). Rats were anesthetized by intraperitoneal injection of $25 \%$ urethane solution (1.0 $\mathrm{g} / \mathrm{kg}$ ), the skin was incised in upper margin of pubic bone to expose the bladder, which was placed at the incision (to avoid the influence of abdominal pressure on pressure of detrusor). Two $24 \mathrm{G}$ catheters were respectively inserted into the bladder from the top wall

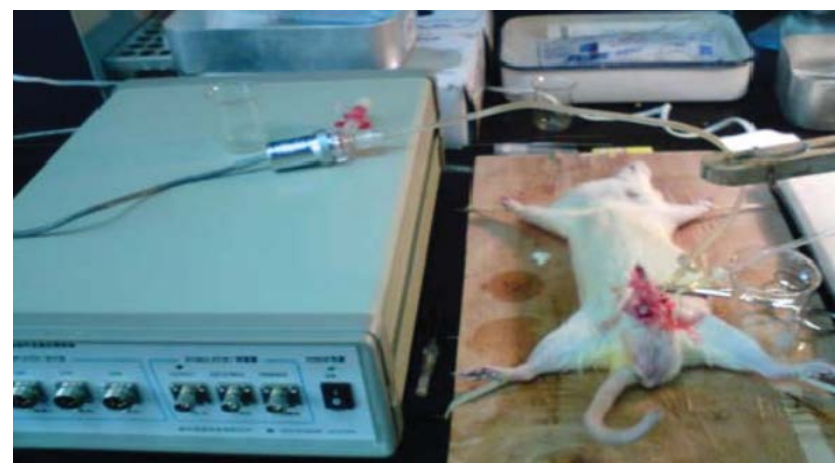

Fig. 1: Medlab urodynamic measurement

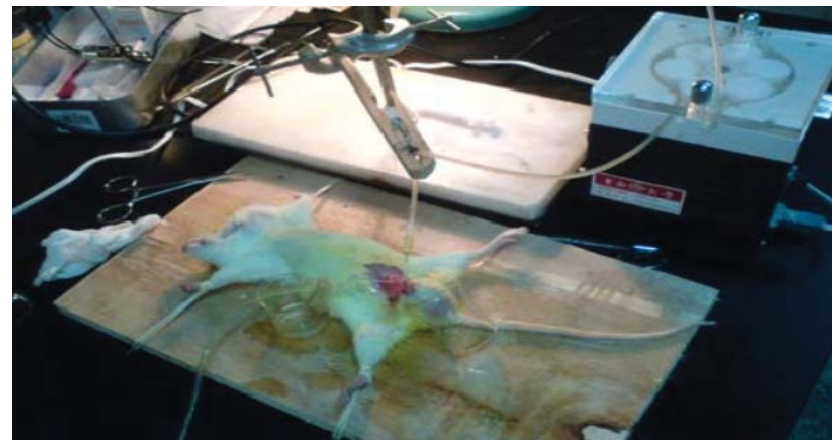

Fig. 2: Micro perfusion assembly of rat bladder

Two $24 \mathrm{G}$ catheters were inserted into the bladder from the top wall and after fixation one end was connected to a micro perfusion pump

Special Issue 1, 2020

Indian Journal of Pharmaceutical Sciences

Special Issue 1, 2020

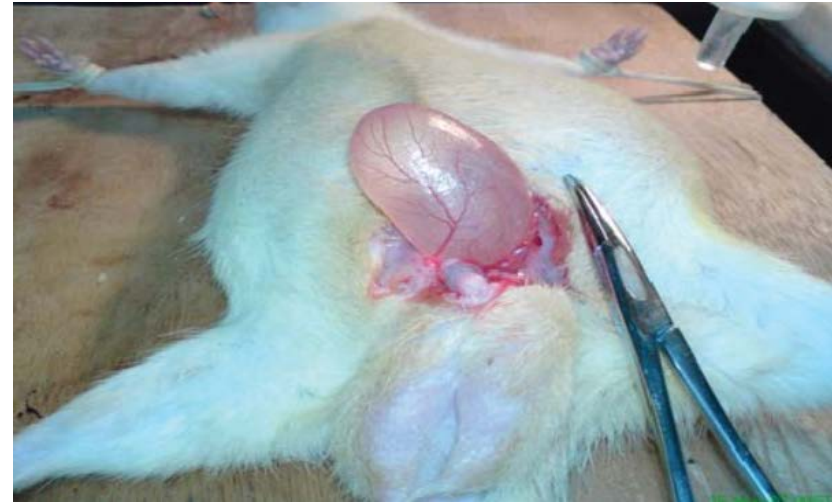

Fig. 3: Bladder pressure/volume determination in rats

and after fixation one end was connected to a micro perfusion pump with intravesical instillation of saline $(0.4 \mathrm{ml} / \mathrm{min})$, and the other end was connected to a MedLab bio-signal collection system through a pressure transducer for determination of bladder pressure. The measurement indicators included the bladder threshold capacity, residual urine, bladder voiding pressure and compliance $(\mathrm{ml} / \mathrm{kpa})$. Measurements were made 3 times from each rat at an interval of $5 \mathrm{~min}$.

After the measurement of bladder pressure/volume, the rats were immediately sacrificed by cervical dislocation and the bladder was weighed. The histological changes and bladder wall thickness were observed under light microscopic, intact bladder specimen was excised, placed in Krebs buffer, the longitudinal muscle at lateral walls was cut, fixed in $10 \%$ formaldehyde solution, and $2 \mathrm{~h}$ after that was cut into $2 \mathrm{~mm}$ segments in length to measure the thickness of bladder wall. It was then dehydrated, made to be transparent, dipped in wax, embedded and sectioned to obtain $5 \mu \mathrm{m}$ sections These sections were baked, dewaxed, stained with Hematoxylin and Eosin, dehydrated and mounted and observed under an optical microscope (200X).

Immediately after sacrifice, superior mesenteric venous blood was collected in sterile tunes from each rat, plasma was separated and stored at $-80^{\circ}$. Radioimmunoassay was used to detect the contents of TNF- $\alpha$ and IL-10 in the plasma of rats. The applied kits are provided by Shanghai Long Kang Biological Technology Co., Ltd., and the operation was conducted strictly according to the kit instructions.

Data were expressed as mean \pm standard deviation and statistical analysis was performed using SPSS 21 statistical software. Significance of the differences were assessed using $t$ test and the level of significance was set at $\mathrm{p}<0.05$. 
TABLE 1: COMPARISON OF URODYNAMIC AND PATHOLOGICAL FINDINGS BETWEEN THE TWO GROUPS

\begin{tabular}{lcccccc}
\hline Group & $\mathrm{n}$ & $\begin{array}{c}\text { Maximum bladder } \\
\text { capacity }(\mathrm{ml})\end{array}$ & $\begin{array}{c}\text { Static bladder } \\
\text { pressure }(\mathrm{kpa})\end{array}$ & $\begin{array}{c}\text { Compliance }(\mathrm{ml} / \\
\mathrm{kpa})\end{array}$ & $\begin{array}{c}\text { Bladder wet } \\
\text { weight }(\mathrm{mg})\end{array}$ & $\begin{array}{c}\text { Bladder wall } \\
\text { thickness }(\mathrm{mm})\end{array}$ \\
\hline Solvent control & 10 & $1.75 \pm 0.23$ & $0.58 \pm 0.13$ & $0.65 \pm 0.07$ & $147.8 \pm 3.56$ & $0.91 \pm 0.05$ \\
group & & $3.61 \pm 0.65$ & $0.97 \pm 0.16$ & $1.43 \pm 0.09$ & $186.4 \pm 4.35$ & $1.43 \pm 1.28$ \\
Carbachol group & 10 & 6.093 & 7.225 & 8.036 & 7.561 & 6.047 \\
$\mathrm{t}$ & & $<0.05$ & $<0.05$ & $<0.05$ & $<0.05$ & $<0.05$ \\
$\mathrm{p}$ & & & & &
\end{tabular}
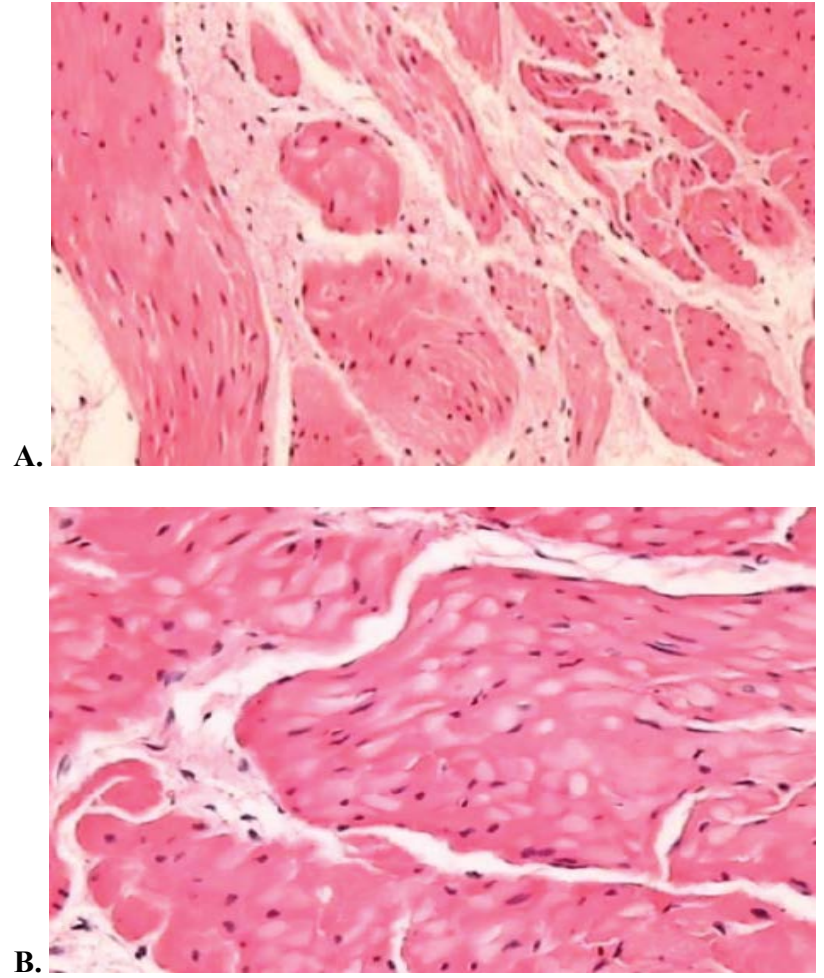

Fig. 4: Light microscopic observation of (A) control rat detrusor muscle sections and (B) carbachol group rat detrusor muscle sections

A: the size, arrangement and shape of detrusor muscle cells in the solvent control group were in order, B: in the carbachol group rat bladder the detrusor cells showed hypertrophy together with disordered arrangement, diverse morphology and vacuolar degeneration of muscle fiber (HE staining, 200X)

The maximum bladder capacity, static bladder pressure, compliance, bladder wet weight and bladder wall thickness in the carbachol group were significantly higher than those in the solvent control group $(\mathrm{p}<0.05)$, as shown in Table 1. Light microscopy revealed that the detrusor cells in the solvent control group appeared to be in order in terms of size, arrangement and shape as shown in fig. 4A; while in the carbachol group eosinophilic infiltration was obviously seen in submucosa with slight mucoid degeneration in muscular layer and the detrusor cells exhibited hypertrophy with disordered arrangement, diverse morphology and vacuolar degeneration of muscle fibre;
TABLE 2: COMPARISON OF LEVELS OF PLASMA INFLAMMATORY MEDIATORS BETWEEN THE TWO GROUPS

\begin{tabular}{lccc}
\hline Group & $\mathrm{n}$ & $\begin{array}{c}\text { TN F-a } \\
(\mu \mathrm{g} / \mathrm{l})\end{array}$ & $\begin{array}{c}\mathrm{IL}-10 \\
(\mu \mathrm{g} / \mathrm{l})\end{array}$ \\
\hline Solvent control group & 10 & $0.86 \pm 0.12$ & $0.75 \pm 0.06$ \\
Carbachol group & 10 & $0.63 \pm 0.18$ & $0.57 \pm 0.09$ \\
$\mathrm{t}$ & & 7.392 & 7.044 \\
$\mathrm{p}$ & & $<0.05$ & $<0.05$ \\
\hline
\end{tabular}

local collagen denaturation as well as fibre degradation were seen in smooth muscle tissues with obvious sponge-like changes in cytoplasm of local muscle cells and moderately more interstitial fibrous proliferation, as shown in fig. 4B.

The levels of TNF- $\alpha$ and IL-10 in plasma of the carbachol group were significantly lower than those of the solvent control group $(\mathrm{p}<0.05)$, as shown in Table 2. For the bladder, when the autonomic nerves are excited, noradrenaline gets released from the nerve terminals and acts on $\beta 3$ receptor of detrusor muscle causing relaxation ${ }^{[7]}$. In the bladder wall has cholinergic innervation, and the acetylcholine released stimulates the MCR on detrusor to cause contraction of bladder ${ }^{[8]}$. The experiments on isolated bladder of various animals including humans showed that the contraction of bladder under physiological conditions mainly involved the M3 choline receptor ${ }^{[9]}$. When the isolated bladder of rats with M3 cholinergic receptors knockout was studied, it was found that cholinergic agonists mediated the contractile response of bladder mainly through the M3 cholinergic receptor ${ }^{[10-12]}$. The results of this study showed that the maximum bladder capacity, static bladder pressure, compliance, bladder wet weight and bladder wall thickness in the carbachol group were significantly higher than those in the solvent control group $(\mathrm{p}<0.05)$, suggesting that carbachol can slow the micturition frequency and prolong the time of bladder perfusion, increase perfusion volume and increase the volume of bladder before the next time of micturition reflex. 
With the development of cell biology and molecular biology, the study of biological function on the whole has attracted more and more attention. Because of the relatively large body weight, rats and guinea pigs are currently common animal models established for analysing drug effects by cystometry in the country ${ }^{[13]}$. In this study, this approach was successfully applied to rats, observed the influence of carbachol and isoproterenol on bladder function through tail vein injection and found that the basic mechanism for micturition control of rats under anaesthesia is similar with that of human.

Related studies ${ }^{[14]}$ have shown that the binding of acetylcholine to nicotinic receptor can reduce the immune activity of macrophages to lipopolysaccharide and inhibit the synthesis of protein after transcription of $\mathrm{TN}$ and the subsequent clinical trial has confirmed that cholinergic agonist nicotine has a therapeutic effect on colitis. There is also a study finding that direct electrical stimulation of efferent pneumogastric nerve in rats with endotoxic shock can inhibit the production of inflammatory mediators in the liver and lung tissues ${ }^{[15]}$, alleviate the pathological damage of lung and slow down the release of oxygen free radicals. Since this antiinflammatory pathway is involved with acetylcholine, it was refer to as the cholinergic antiinflammatory pathway, whose main mechanism is to mobilize the neuroendocrine immune system in body to modulate inflammatory response. However, there remain many problems in cholinergic antiinflammatory pathway during the process of treatment, for example direct stimulation of vagus nerve not only causes damages to the nerve itself, but also gives rise to fluctuation of breathing, heart rate and blood pressure ${ }^{[16]}$. The application of cholinergic drugs enables to achieve the same antiinflammatory effect with higher safety. Carbachol used in this experiment is a powerful cholinergic drug, which binds to $\mathrm{M}$ and $\mathrm{N}$ cholinergic receptors and has the full Ach-like function with longer duration. It has a moderately strong effect on exciting the stomach and intestine as well as bladder smooth muscle. The study results showed that the levels of TNF- $\alpha$ and IL-10 in the carbachol group were lower than those in the solvent control group $(p<0.05)$, suggesting that carbachol can effectively reduce the content of TNF- $\alpha$ and IL-10 in plasma and inhibit release of proinflammatory factors of TNF- $\alpha$ and IL-10 with alleviation of inflammation and that its mechanism may be related to the fact that carbachol excites cholinergic $\mathrm{N}$ receptor so as to play a Ach-like effect. In summary, in anesthetized rats, the stimulation of MCR can significantly reduce urinary frequency, increase the volume of bladder storage and decrease systemic inflammatory response.

\section{Conflict of interest:}

No conflict of interest between any of the authors.

\section{REFERENCES}

1. Ghoncheh M, Pournamdar Z, Salehiniya H. Incidence and mortality and epidemiology of breast cancer in the world. Asian Pac J Cancer Prev 2016;17:43-6.

2. Sitlinger A, Shelby RA, Van Denburg AN, White H, Edmond $\mathrm{SN}$, Marcom PK, et al. Higher symptom burden is associated with lower function in women taking adjuvant endocrine therapy for breast cancer. Geriatr Oncol 2019;10:317-21.

3. Gali-Muhtasib H, Hmadi R, Kareh M, Tohme R, Darwiche N. Cell death mechanisms of plant-derived anticancer drugs: beyond apoptosis. Apoptosis 2015;20:1531-62.

4. Shi H, Liu J, Tu Y, Freter CE, Huang C. Oolong tea extract induces DNA damage and cleavage and inhibits breast cancer cell growth and tumorigenesis. Anticancer Res 2018,38:6217-23.

5. Nagini S. Breast cancer: current molecular therapeutic targets and new players. Anticancer Agents Med Chem 2017;17: 152-63.

6. Henry D, von Moos R, Body JJ, Rider A, De Courcy J, Bhowmik D, et al. Bone-targeted agent treatment patterns and the impact of bone metastases on patients with advanced breast cancer in the United States. Curr Med Res Opin 2019;14:1-16.

7. Kim E, Andersen MR, Standish LJ. Comparison of healthrelated quality of life between adjuvant breast cancer treatment groups. Oncol Nurs Forum 2019;46:59-70.

8. Liu J, Guo W, Tong M. Intraoperative indocyanine green fluorescence guidance for excision of nonpalpable breast cancer. World J Surg Oncol 2016;14:266.

9. Biehler-Gomez L, Giordano G, Cattaneo C. The appearance of breast cancer metastases on dry bone: Implications for forensic anthropology. Forensic Leg Med 2019;61:5-12.

10. Baraya YS, Wong KK, Yaacob NS. The immunomodulatory potential of selected bioactive plant-based compounds in breast cancer: a review. Anticancer Agents Med Chem 2017;17:770-83.

11. Lazzeroni M, Guerrieri-Gonzaga A, Gandini S, Johansson H, Serrano D, Cazzaniga M, et al. A presurgical study of lecithin formulation of green tea extract in women with early breast cancer. Cancer Prev Res 2017;10:363-70.

12. Mustafa M. Antibacterial efficacy of neem (Azadirachta indica) extract against enterococcus faecalis: an in vitro study. J Contemp Dent Pract 2016;17:791-4.

13. Wu Q, Kohli M, Bergen HR 3rd, Cheville JC, Karnes RJ, $\mathrm{Cao} \mathrm{H}$, et al. Preclinical evaluation of the supercritical extract of Azadirachta indica (neem) leaves in vitro and in vivo on inhibition of prostate cancer tumor growth. Mol Cancer Ther 2014;13:1067-77.

14. Pei Z, Fu W, Wang G. A natural product too sendanin inhibits epithelial-mesenchymal transition and tumor growth in pancreatic cancer via deactivating Akt/mTOR signaling. Biochem Biophys Res Commun 2017;493:455-60.

15. Quelemes PV, Perfeito ML, Guimarães MA, dos Santos RC, Lima DF, Nascimento C, et al. Effect of neem (Azadirachta 
indica A. Juss) leaf extract on resistant Staphylococcus aureus biofilm formation and Schistosoma mansoni worms. J Ethnopharmacol 2015;175:287-94.

16. Kai W, Yating S, Lin M, Kaiyong Y, Baojin H, Wu Y, et al. Natural product toosendanin reverses the resistance of human breast cancer cells to adriamycin as a novel PI3K inhibitor. Biochem Pharmacol 2018;152:153-64.

17. Zheng MD, Wang ND, Li XL, Yan J, Tang JH, Zhao XH, et al. Toosendanin mediates cisplatin sensitization through targeting Annexin A4/ATP7A in non-small cell lung cancer cells. Nat Med 2018;72:724-33.

18. Zhou Q, Wu X, Wen $\mathrm{C}$, Wang $\mathrm{H}$, Wang $\mathrm{H}$, Liu $\mathrm{H}$, et al. Toosendanin induces caspase-dependent apoptosis through the p38 MAPK pathway in human gastric cancer cells. Biochem Biophys Res Commun 2018;505:261-6.

19. Arumugam A, Agullo P, Boopalan T, Nandy S, Lopez $\mathrm{R}$, Gutierrez, et al. Neem leaf extract inhibits mammary carcinogenesis by altering cell proliferation, apoptosis, and angiogenesis. Cancer Biol Ther 2014;15:26-34.

20. Zhang S, Cao L, Wang ZR, Li Z, Ma J. Anti-cancer effect of toosendanin and its underlying mechanisms. Asian Nat Prod Res 2019;21:270-83.

21. Alečković M, Kang Y. Regulation of cancer metastasis by cell-free miRNAs. Biochim Biophys Acta 2015;1855:24-42.

22. Kang JH, Choi MY, Cui YH, Kaushik N, Uddin N, Yoo KC, et al. Regulation of FBXO4-mediated ICAM-1 protein stability in metastatic breast cancer. Oncotarget 2017;8:83100-13.

23. Kwon KM, Chung TW, Kwak CH, Choi HJ, Kim KW, Ha SH, et al. Disialyl GD2 ganglioside suppresses ICAM-1-mediated invasiveness in human breast cancer MDA-MB231 cells. Int J Biol Sci 2017;13:265-75.

24. Guo P, Yang J, Jia D, Moses MA, Auguste DT. ICAM-1Targeted, Lcn2 siRNA-Encapsulating Liposomes are Potent Anti-angiogenic Agents for Triple Negative Breast Cancer. Theranostics 2016;6:1-13.
25. Puzovic V, Brcic I, Ranogajec I, Jakic-Razumovic J. Prognostic values of ETS-1, MMP-2 and MMP-9 expression and co-expression in breast cancer patients. Neoplasma 2014;61:439-46.

26. Merdad A, Karim S, Schulten HJ, Dallol A, Buhmeida A, AlThubaity F, et al. Expression of matrix metalloproteinases (MMPs) in primary human breast cancer: MMP-9 as a potential biomarker for cancer invasion and metastasis. Anticancer Res 2014;34:1355-66.

27. Yun EJ, Song KS, Shin S, Kim S, Heo JY, Kweon GR, et al. Docosahexaenoic acid suppresses breast cancer cell metastasis by targeting matrix-metalloproteinases. Oncotarget 2016;7:49961-71.

28. Xu H, Li M, Zhou Y, Wang F, Li X, Wang L, et al. S100A4 participates in epithelial-mesenchymal transition in breast cancer via targeting MMP2. Tumour Biol 2016;37:2925-32.

29. Abdelmawgoud H, El Awady RR. Effect of Sirtuin 1 inhibition on matrix metalloproteinase 2 and Forkhead box O3a expression in breast cancer cells. Genes Dis 2017;4:240-6.

30. Reggiani F, Labanca V, Mancuso P, Rabascio C, Talarico G, Orecchioni S, et al. Adipose Progenitor Cell Secretion of GM-CSF and MMP9 Promotes a Stromal and Immunological Microenvironment That Supports Breast Cancer Progression. Cancer Res 2017;77:5169-82.

This is an open access article distributed under the terms of the Creative Commons Attribution-NonCommercial-ShareAlike 3.0 License, which allows others to remix, tweak, and build upon the work non-commercially, as long as the author is credited and the new creations are licensed under the identical terms

This article was originally published in a special issue, "XXXXXX"

Indian J Pharm Sci 2020:82(1)spl issue1; XX-XX 